\title{
СИСТЕМА ПЕДАГОГИЧЕСКОГО УПРАВЛЕНИЯ ОБУЧЕНИЕМ ДВИГАТЕЛЬНЫМ ДЕЙСТВИЯМ СТУДЕНТОВ ИНСТИТУТОВ ФИЗИЧЕСКОЙ КУЛЬТУРЫ
}

\section{PEDAGOGICAL CONTROL SYSTEM OF TRAINING MOTOR ACTIONS OF STUDENTS OF INSTITUTES OF PHYSICAL CULTURE}

Wang Tong

Summary: The article presents the leading characteristics of the control system for teaching motor actions to students of a physical education university. The analysis of the results obtained in the course of research carried out within the framework of the given topic demonstrated a high level of interest in the theory and practice of pedagogical management of motor actions in the development of a control system that can significantly improve the efficiency and quality of the process of teaching students motor actions. The use of the pedagogical management system can significantly facilitate the task of implementing the educational process aimed at mastering students ' motor actions and individualizing pedagogical influences. In the context of the above, we can conclude that it is relevant to develop a scientifically based algorithm for controlling the training of motor actions, monitoring and correcting programs of pedagogical influence.

Keywords: motor actions, leading systems, teacher, pedagogical management of training.

\section{Введение}

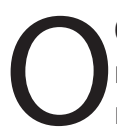
бучение, осуществляемое в ходе физического воспитания, ориентировано на достижение конкретного уровня образованности в области физической культуры, которое подразумевает «<... системное освоение человеком рациональных способов управления двигательными действиями необходимыми в качестве фонда двигательных знаний, умений, навыков, значимых в его жизнедеятельности» [4]. Реализация педагогического процесса, осуществляемого в рамках дисциплин спортивной направленности, предусматривает обучение занимающимися различным двигательным действиям, что в итоге позволяет им осуществлять контроль и, соответственно, управление своими движениями. Кроме названного, процесс физического воспитания студентов подразумевает познание закономерностей двигательных действий, что позволяет рационализировать большинство движений, осуществляемых в профессиональной и бытовой сферах [5].

\author{
Ван Тун \\ Аспирант, Российский Государственный Университет \\ Физической Культуры, Спорта, Молодежи и Туризма \\ (ГЦОЛИФК) \\ tun.van.90@mail.ru
}

Аннотация: В статье представлены ведущие характеристики системы управления обучением двигательным действиям студентов физкультурного вуза. Анализ результатов, полученных в ходе исследований, осуществленных в рамках заданной темы, продемонстрировал высокий уровень заинтересованности теории и практики педагогического управления двигательными действиями в разработке системы управления, позволяющей существенно повысить эффективность и качество процесса обучения студентов двигательным действиям. Применение системы педагогического управления способно значимо облегчить задачу реализации образовательного процесса, направленного на освоение студентами двигательных действий и индивидуализации педагогических воздействий. В контексте сказанного, можно сделать вывод 06 актуальности разработки научно обоснованного алгоритма управления обучения двигательным действиям, осуществления контроля и коррекции программ педагогического воздействия.

Ключевые слова: двигательные действия, ведущие системы, преподаватель, педагогическое управление обучением.
Освоение различных видов двигательной деятельности, которое предусматривает определение наиболее характерной особенности проявления координационных усилий и проявление во вне индивидуально обусловленной степени нервно-мышечного напряжения, значимо в контексте решения двигательных задач, характеризуемых точностными параметрами, т.е. предусматривающих конкретное дозирование и соответствие пространственной ориентации [2, 3]. Опираясь на сказанное, педагогический процесс, ориентированный на освоение двигательных действий, можно представить в виде управления взаимосвязями, существующими между отдельными элементами целостной системы «учебная программа - преподаватель - средства и методы обучающийся».

Ключевую позицию в вышеназванной системе управления занимает преподаватель, осуществляющий специальные педагогические воздействия путем использования соответствующих задачам средств физического воспитания. Профессиональная компетентность препо- 
давателя определяет степень обеспеченности необходимыми взаимосвязями реакций студента, что выступает в качестве одного из условий успешного освоения им двигательных действий, установленных программой подготовки специалиста.

В контексте сказанного следует признать нереальность установления контроля над всеми параметрами двигательной структуры действия обучающегося и обеспечения их системного проявления в соответствии с «идеальной» моделью, в результате чего, первоначально следует обратить внимание на основные факторы двигательного действия, индивидуальные особенности обучаемого и специфику их различий при сравнении с модельными характеристиками.

\section{Теоретическое обоснование проблемы исследования}

Общеизвестным является факт трансляции поступаемой из вне (от преподавателя) информации к обучаемому, воспринимаемой им в виде субъективных ощущений и представлений о правильном / ошибочном выполнении двигательного действия. Преподаватель, опираясь на ранее установленные пространственно-временные параметры двигательного действия, его направления и амплитуды, контролирует соответствие его исполнения с целью своевременной корректировки в случае необходимости, т.е. при совершении ошибки в выполнении двигательного действия обучающимся.

Выполнение двигательных действий обучающимся позволяет установить его текущее состояние путем проведения сравнения действий студента с заданной «идеальной» моделью его исполнения. Контроль за соблюдением соответствия осуществляет преподаватель, опираясь на ранее освоенные им знания в области профессионально деятельности, и педагогические умения, выражающиеся в оптимальном отборе и рациональном применении адекватных средств и методов.

Результативность освоения двигательных действий определяется через систему показателей, характеризующих координационную сложность, физическую трудность и психическую напряженность конкретного двигательного акта [1]. При этом, важное значение в контексте сказанного приобретает результативное управление процессом обучения двигательных действий, которое достигается посредством составления «рисунка» плана обучения, представленного: 1) динамичной программой конкретных двигательных заданий, соответствующих учебной; 2) системой контроля, направленного на обеспечение систематическое поступление значимой с точки зрения освоения знаний информации в системе «педагог обучающийся»; 3) коррекцией процесса обучения, опираясь на организованную обратную связь в системе «педагог обучающийся».

Профессиональная деятельность преподавателя выстраивается по конкретному алгоритму, позволяющему достигать намеченной образовательной цели. Цель определяет формирование частных задач, предмета обучения, освоение которого следует предоставить студентам, условия, позволяющие на практике реализовать учебную программу в разделе освоения обучающимися двигательных действий, и количественные показатели, сравнение с которыми позволяет установить степень достижения намеченной образовательной цели и решение поставленных задач.

Однако первоначально, действия преподавателя (педагога) направлены на составление представления о каждом конкретном занимающимся и создание наиболее благоприятной обстановки для реализации плана обучения. В ходе формирования представлений об обучающихся, преподаватель отмечает ведущие и вспомогательные факторы, требующие предварительной проверки знаний, двигательных умений и навыков, что в совокупности позволяет создать общую картину психофизических способностей студентов. Непосредственно цель и задачи обучения студентов двигательным действиям устанавливается в ходе сопоставления сложившегося представления о студентах и образцом техники двигательного задания, что в последующем раскрывается в системе частных задач, подбираются средства и методы с целью их разрешения (см. рисунок 1).

\section{BывоА}

Установление условий, позволяющих на практике реализовать обучающий процесс по освоению двигательных действий, содействует конкретизации выбора вероятностных ситуаций, которые в полной мере соответствуют причинам допущения ошибок в выполнении, а значит определяют конечный результат процесса обучения. Применение в качестве оценочного инструментария количественных критериев (чаще всего 5-балльная шкала оценки) предоставляет возможность определение временного периода деятельности, направленной на совершенствование двигательных действий в условиях повышения психофизических усилиях, устанавливая критерии выбора оптимальных средств и методов, содействующих развитию двигательных способностей и волевых качеств студентов.

Вышеуказанные двигательные задания, включенные в состав программы двигательных действий позволяю установить степень достижения изначально заданной цели педагогического процесса, а оставшиеся подсистемы демонстрируют решение промежуточных задач, совокупность которых позволяет достичь общей цели обучения. 


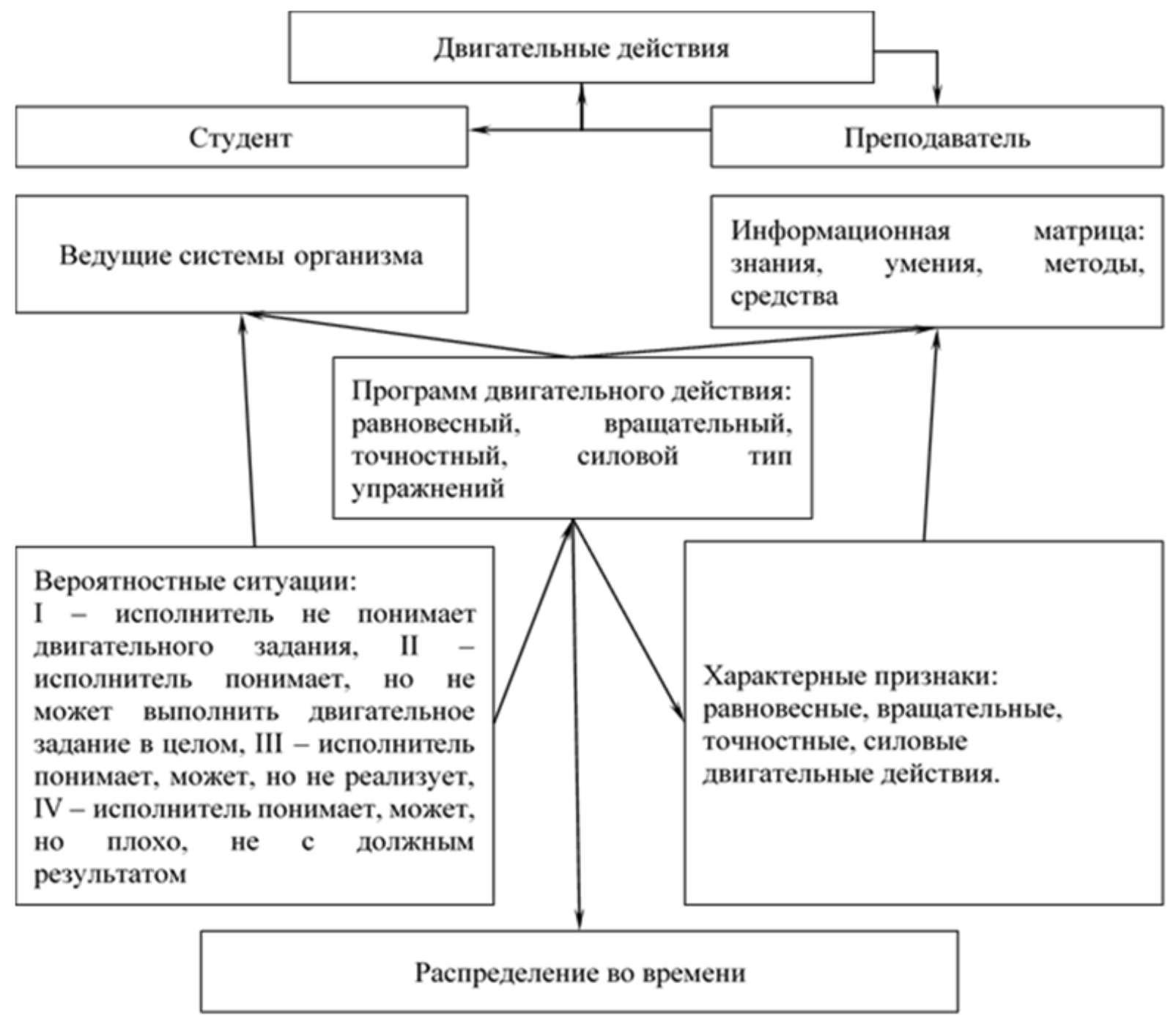

Рис. 1. Система педагогического управления обучением двигательным действиям

Анализ результатов, полученных в ходе исследований, осуществленных в рамках изучаемой темы, продемонстрировал высокий уровень заинтересованности теории и практики педагогического управления двигательными действиями в разработки подобной системы управления, позволяющей существенно повысить эф- фективность и качество процесса обучения. Таким образом, использование системы педагогического управления способно значимо облегчить задачу реализации образовательного процесса, направленного на освоение студентами двигательных действий и индивидуализации педагогических воздействий.

\section{ЛИТЕРАТУРА}

1. Алиходжин Р.Р. Обучение двигательным действиям студентов РУт (МИИТ) с использованием критериев трудности // Ученые записки университета имени П.Ф. Лесгафта. - 2020. - № 5 (159). - С. 19-22.

2. Бальсевич В.К., Запорожанов В.А. Физическая активность человека. - Киев: Здоровье, 2018. - 424 с.

3. Бернштейн Н.А. Очерки по физиологии движений и физиологии активности. - М.: Медицина, 2015. - 58 с.

4. Курамшин Ю.Ф. Теория и методика физической культуры: учебник для ИФК. - М.: Советский спорт, 2014. - 464 с.

5. Холодов Ж.К., Кузнецов В.С. Теория и методика физического воспитания и спорта: учебное пособие для студентов высших учебных заведений. М.: Академия, 2001. -480 c. 